\title{
Sorption of Methylene Blue onto Sugarcane Bagasse: A Column Study
}

\author{
Noor Afifah Husna Md Hussain ${ }^{1}$, Jurina Jaafar ${ }^{2}$, Shariff Che Ibrahim ${ }^{3}$,AminuddinMohd Baki ${ }^{4}$, \\ Zulhafizal Othman ${ }^{5}$,Suzana Ramli ${ }^{6}$,Wardah Tahir ${ }^{7}$ \\ ${ }^{1}$ Faculty of Civil Engineering, UniversitiTeknologi MARA, Shah Alam, Selangor Malaysia \\ ${ }^{2}$ Faculty of Civil Engineering, UniversitiTeknologi MARA, Shah Alam, Selangor Malaysia, jurina@ uitm.edu.my \\ ${ }^{3}$ Faculty of Applied Science, UniversitiTeknologi MARA, Shah Alam, Selangor Malaysia, sha88@uitm.edu.my \\ ${ }^{4}$ Envirab Services ,P.O.Box 7866, GPO Shah Alam, Selangor Malaysia \\ ${ }^{5}$ Faculty of Civil Engineering, UniversitiTeknologi MARA Pahang Banch,Jengka Campus, Pahang Malaysia, \\ zulhafizal445@uitm.edu.my \\ ${ }^{6}$ Faculty of Civil Engineering, UniversitiTeknologi MARA, Shah Alam, Selangor Malaysia, suzana799@uitm.edu.my \\ ${ }^{7}$ Faculty of Civil Engineering, UniversitiTeknologi MARA, Shah Alam, Selangor Malaysia,warda053@uitm.edu.my
}

\begin{abstract}
Methylene blue (MB) is a cationic dye that consists of complex organic molecular which is hard to biodegrade and involves several processes to remove as it is resisted to any detergents. MB is one of the pollutants found in wastewater and in natural stream. The undesirable color has prevented the sunlight pass through the surface of a stream. This has led to eutrophication that harmful to the aquatic life. This paper presents the sorption of MB onto the sugarcane bagasse. In this study, the locally accessible cellulose, hemicellulose and lignin-rich agricultural by-product sugarcane bagasse (SB) for the elimination of dye from aqueous solution. The SB is found to be an efficient media for the removal of dye from wastewater. In this study, the column with $1.5 \mathrm{~cm}$ diameter, different bed depths at 3,5 and $7 \mathrm{~cm}$ has proven can treat 160, 300 and $400 \mathrm{ml}$ of wastewater; with $\mathrm{MB}$ concentration of $50 \mathrm{mg} / \mathrm{l}$ with the column flow rate at 2.5 $\mathrm{ml} / \mathrm{min}$. The adsorption bed exhausted within a very short with $(\sim 1$ h) after the breakthrough occurred. This indicated that the adsorption zone is almost saturated at the time of exhaustion. The effect of flow rate from the column study is also studied at different flow rate at $1.5,2.5$ and $3.5 \mathrm{ml} / \mathrm{min}$ and to treat 665,300 and $250 \mathrm{ml}$ wastewater respectively with $\mathrm{MB}$ concentration of $50 \mathrm{mg} / \mathrm{l}$ and bed depth maintained at $5 \mathrm{~cm}$. Maximum adsorption of SB is at the highest bed depth and the lowest flow rate in the bed depth and flow rate study respectively. The plotted breakthrough curves obtained from experimental data issimilar to the typical breakthrough curve. The results obtained has been applied to Thomas and Yoon-Nelson model, which best fitted with $\mathrm{R}^{2}$ value in range $0.95-1.00$ and the time taken for breakthrough is similarly close to model prediction value. The results indicated that SB is an ideal alternative for dye removal from wastewater.
\end{abstract}

Key words : Methylene Blue, adsorption, sugarcane bagasse, fixedbed column, breakthrough curve, Thomas and Yoon-Nelson models.

\section{INTRODUCTION}

Nowadays, the industrialization and urbanization has been rapidly growth throughout time. This matter is slowly depleting the important of water which they are susceptible to contaminants from effluent discharge from numerous industrial activities. The disposal of liquid dyes effluent from various industries have received special attention by environmentalists. Untreated or partially treated waste waters and industrial effluent discharged in natural ecosystems cause a serious problem to the ecosystem. Liquid dyes from textile and dyestuff industries areintractable. This is because dyes have a synthetic and complex aromatic molecular structure, which makes the structure more stable and difficult to biodegrade [1]. Besides having possible harmful effects, dying materials in water are aesthetically unpleasant. The dyes used in the textile industries include several structure varieties such as acidic, reactive, basic, disperse, azo, diazo, anthraquinone based and metal complex dyes [2]. In the present study, methylene blue (MB) a basic dye is selected as a model compound in order to evaluate the capacity of the sugarcane bagasse (SB) for the removal of MB from solutions. Methylene blue (MB), which is the most common among all other dyes of its category, is generally used for dyeing cotton and silk. Methylene blue is a moderate hazardous substance and can cause some harmful effects. Acute exposure to methylene blue can cause heart rate increase, vomiting, shock, Heinz body formation, cyanosis, jaundice, quadriplegia, and tissue necrosis in humans [3].

The dye removal from industrial effluents usedthe methods called adsorption, chemical coagulation, flocculation, precipitation, chemical oxidation, froth floatation, ozonation, reverse osmosis and biological techniques [4]. Adsorption has been found to be superior to other techniques for water re-use in terms of initial cost, flexibility and simplicity of design, more simplified operation and insensitivity to toxic pollutants. Due to its effectiveness and versatility, activated carbon as adsorbent is widely employed in water and wastewater treatment. However, the operating cost is high. This has been preliminary stage for manystudies to identified for more economic adsorbents [5].

One of the compelling techniques to eliminate organic impurity and inorganic in drainage system is by the process of adsorption [6]. The process of molecular tie onto the surface 
is called adsorption. It depends on how the solids are preferred to absorb other soluble solids from the solution. In view of agricultural decay as a substitute for dye removal are studied over decades, these cost-effective adsorbentis developed [7], [8]. Agricultural waste offers cheap and widely available, the ease in technology, and biodegradable production. The sugarcane bagassefrom an agricultural waste is used in this study.Breakthrough studies that focused on the flow rate and bed depthare conducted to evaluate the performance of SB in continuous fixed-bed operation. The breakthrough curve for the adsorption of $\mathrm{MB}$ are analyze using Thomas and Yoon-Nelson model.

In general, this study evaluates the applicability of sugarcane bagasse as an adsorbent for the removal of dyes in wastewater. The study has been conducted with specific objectives which are to determine effect of column parameters for the dye removal by sugarcane bagasse and o fit the experimental data to the column mathematical models, such as Thomas and Yoon-Nelson.

This research is constructed to achieve the objectives of the study. In addition, it is satisfying to design environmental sustain absorbent to treat wastewater in order to remove the MB. Moreover, this research is to explore on the numerous parameters effect as in the effect on different bed depth of adsorbent (3, to $7 \mathrm{~cm})$ and the effect of different inlet flow rate $(1.5$ to $3.5 \mathrm{ml} / \mathrm{min})$. The column study experiment is conducted to determine the various plots of breakthrough under numerous process conditions. By implementing Thomas and Yoon-Nelson kinetic models in this research study, the breakthrough curves (BTCs) on the MB adsorption areanalysed.The adsorption of dyes depends on the dye traits which is the molecular structure and the type, number and position of the substituents in the dye molecule. Agricultural solid waste materials, which are cheaper than activated carbon can be found easily and also can be directly used as adsorbents or partial treatment. The advantages of using agricultural solid waste as an adsorbent, includes the cheaper in cost, the efficiency is high, it can minimize the chemical and biological sludge, and the possibility of dye recovery.

Hence, the significance of this research study is to search for another environmental friendly and economic agricultural solid waste to adopt adsorbent for dyes wastewater treatment since it is easily accessible and has no value. The purpose of this study is to make use of sugarcane in order to remove MB in more effective and inexpensive way. Besides that, sugarcane as an adsorbents are also useful in the term of removing the matters of organic and inorganic from industrial effluent. Furthermore, by having this research can help to improve the understanding of people towards the important of this study which can give a lot of benefit towards the water and wastewater in the future. Moreover, it also can improve the quality of water and prevents water pollution.

\section{MATERIAL AND METHODOLOGY}

\subsection{Preparation of sugarcane bagasse}

Sugarcane bagasse (SB) has been collected from local market in Shah Alam, Selangor. The distilled water is used as a cleaning process of SB from dust and impurity of SB. SB needed to be air-dried under and take to oven dried overnight at $60^{\circ} \mathrm{C}$. The dried SBis grinded using a food processor and sieved to $1 \mathrm{~mm}$ mesh size.

\subsection{Preparation of aqueous dye solution}

Methylene Blue dye (MB) istaken from FriendemannSchmidtis used. In this study, the MB did not requirethe process of purification. Stock solution of dye is prepared by dissolving $50 \mathrm{mg}$ of dye in $1000 \mathrm{ml}$ double distilled water. Methylene Blue dye is cationic dye in nature and its dmaxis $668 \mathrm{~nm}$.

\subsection{Spectrophotometer}

Spectrophotometer (Shimadzu Brand UV-3000) is used to determine the MB's concentration in the solution and the analysis is done by observing the absorbance differences at a wavelength of maximum absorbance $(668 \mathrm{~nm})$.

\subsection{Calibration curve}

Figure 1 shows the calibration curve plot on adsorption of MB dye concentration ranging from 0.00 to $12.50 \mathrm{ppm}$ with regression coefficient value of 0.9993 .

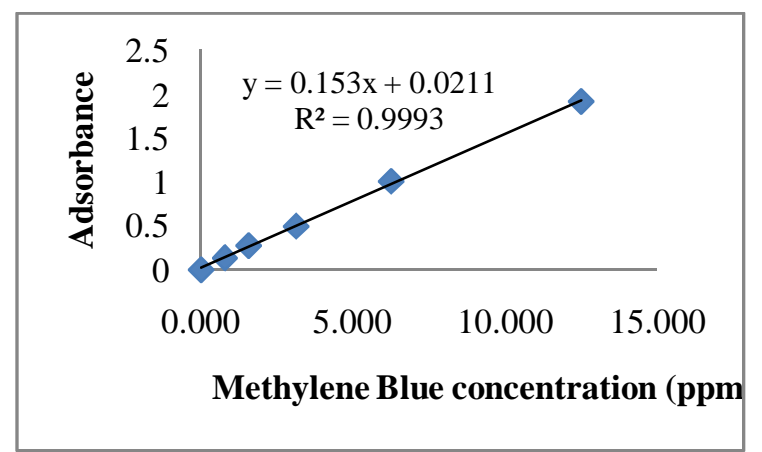

Figure 1: UV Calibration curve plot for MB adsorption

\subsection{General column study}

The experimental arrangement consist of a peristaltic pump, a reservoir containing dye stock solution, a $14 \mathrm{~mm}$ diameter silicon tube delivery line to convey dye solution from reservoir to the column, adsorbent packed column and vials functioned as the sampling point as shown in Figure 2. Fixed bed column study is performed by polypropylene cylindrical plastic columns with $1.5 \mathrm{~cm}$ and $7.5 \mathrm{~cm}$ in diameter and height, respectively. The column then is occupied with $1 \mathrm{~mm}$ in bed height of net cloth at the bottom and top section to hold the adsorbent whilst secured homogenous distribution of the feed solution. By using a size 14 silicon tube Cole Palmer Masterflex peristaltic pump, $50 \mathrm{ppm}$ stock solution dye is charged in the down flow mechanism at desired flow rate. Samples of column runoff are collected in intervals using vials and are examine for absorbance. The column operation eliminated once the introductory concentration value of effluent MB concentration exceeds $99.5 \%$ as suggested by [5]. 


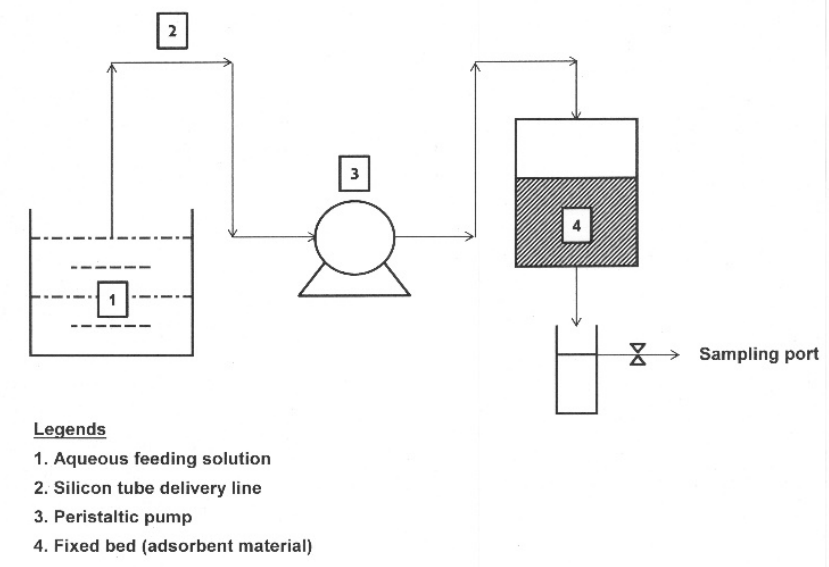

Figure 2: Column system schematic drawing

\subsection{Effect column parameters}

Two operating parameters are studied. In effect of bed depth study, different volume of adsorbent is packed into the column in each run to provide 3,5 and $7 \mathrm{~cm}$ bed depth, as the flow rate and $\mathrm{MB}$ concentration maintained to $2.5 \mathrm{ml} / \mathrm{min}$ and $50 \mathrm{ppm}$, respectively. Whilst in the effect of flow rate study, the analogous fixed bed experiment is repeated with different flow rate $1.5,2.5$ and $3.5 \mathrm{ml} / \mathrm{min}$ with bed depth and $\mathrm{MB}$ concentration maintained to $5 \mathrm{~cm}$ and $50 \mathrm{ppm}$ respectively.

\subsection{Thomas model}

The Thomas model is used to describe the fixed-bed performancefor $\mathrm{MB}$ removal and the prediction of the concentration-time profile so called the breakthrough curve for the effluent. The input data is a non-linear plot of effluent concentration against sampling time from experiment findings for both bed depth and flow rate study. The output data of this model are the Thomas rate constant $\left(\mathrm{k}_{\mathrm{Th}}\right)$, equilibrium adsorbate uptake $\left(\mathrm{q}_{0}\right)$ and regression coefficient $\left(\mathrm{R}^{2}\right)$. Only $\mathrm{R}^{2}$ is discussed in this column study.

\subsection{Yoon-Nelson model}

Simplifiedtheoretical model developed by Yoon-Nelson is used to study the breakthrough behaviour of MB on sugarcane bagasse. The input data is a non-linear plot of effluent concentration against sampling time from experiment findings for both bed depth and flow rate study. The output data for this model are the Yoon-Nelson rate constant $\left(\mathrm{k}_{\mathrm{YN}}\right)$, the time needed for $50 \%$ adsorbate breakthrough $(\tau)$ and the regression coefficient $\left(R^{2}\right)$. Only $\tau$ and $R^{2}$ are discussed further in this column study. The $\tau$ values from the model represent the time needed for $50 \%$ adsorbate breakthrough and used to compare with the time needed for 50\% adsorbate breakthrough from experiment findings. While the $\mathrm{R}^{2}$ value is the regression coefficient.

\section{RESULTS AND DISCUSSION}

\subsection{Bed depth effect on breakthrough curve}

The column operations is carried out at distinct bed depth which is 3,5 and $7 \mathrm{~cm}$ whilst the $\mathrm{MB}$ concentration and the flow rate is set up to be continuously consistent at $50 \mathrm{ppm}$ and $2.5 \mathrm{ml} / \mathrm{min}$, respectively. As shown in Fig.3, the adsorption bed is exhausted within a very short time $(\sim 1 \mathrm{hr})$ after the breakthrough occurred, which indicated that the adsorption zone is almost saturated at the time of exhaustion. These types of breakthrough curves are highly desirable. The breakthrough times, corresponding to $\mathrm{C} / \mathrm{C}_{0}=0.100$ as suggested by [9] are found to be 6,26 and 42 minutes for 3,5 and $7 \mathrm{~cm}$ bed depth, respectively. The exhausted times, corresponding to $\mathrm{C} / \mathrm{C}_{0}=0.995$ as suggested by [5] are 32,60 and 80 minutes, respectively. The corresponding volumes of wastewater treated at breakthrough point are 30, 130 and 210 $\mathrm{ml}$, respectively and at exhaust point are 160,300 and $400 \mathrm{ml}$, respectively.

In Fig.3, the breakthrough curves showed as depth of the bed increases, the MB has extra time to contact with sugarcane bagasse thus resulted a greater performance of $\mathrm{MB}$ ions removal in the column. Therefore, the solute concentration in the effluent decreased simultaneously with the bed column results increment. A widen mass transfer zone resulted by the breakthrough curve decreasing slope as the bed depths increased. As a result of the increment in the adsorbent surface area, extra attachment sites for adsorption is produced due to the high uptake noticed at the topmost bed depth [10].

As illustrated in Figure 3, common breakthrough curve are plotted to investigate the bed depth effect onto MB removal. From this parameter study, the column parameters information are gathered and tabulated in Table 1. By referring to Table 1, the longest breakthrough time is for $7 \mathrm{~cm}$ bed depth as well which is 42 minutes compared to $3 \mathrm{~cm}$ and $5 \mathrm{~cm}$ which are only 6 and 26 minutes accordingly, thus provide more contact time with adsorbent to adsorb larger volume of MB. This indicates that the lower bed depth reached the breakthrough faster compared to the higher bed depth and the column exhausted time elevated significantly with the bed depth increased. It is observed that the breakthrough curves became steeper as the bed depth reduced. MB adsorption is a quick process, diffusion effects are lower due to the unsatisfactory residence time of dyes in the column at lower bed depth. These evidently show that higher bed depth performance is greater in $\mathrm{MB}$ removal compared with the lower one in column mode.

As shown in Table 1, the column achieved exhaustion condition slower for $7 \mathrm{~cm}$ bed depth which is within 80 minutes compared to 60 and 32 minutes for 5 and $3 \mathrm{~cm}$ bed depth, respectively. In addition, higher bed depth produced larger volume of treated effluent and longer the column service time. This indicates that higher bed depth is more effective to absorb larger amount of MB compared to lower bed depth. 


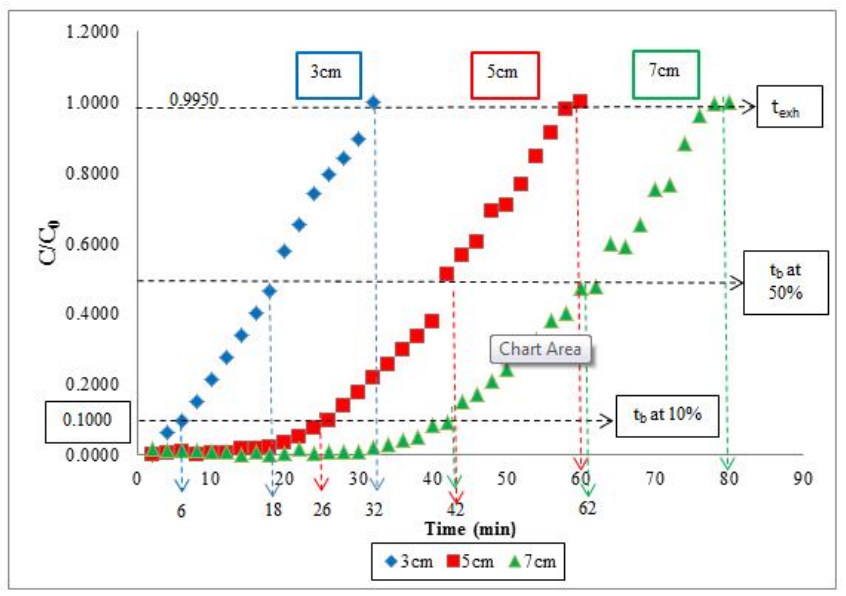

Figure 3: Bed depth effect breakthrough curve on sugarcane bagasse $\mathrm{MB}$ adsorption at $\mathrm{C}_{0}=50 \mathrm{mg} / \mathrm{L}$ and $2.5 \mathrm{ml} / \mathrm{min}$ flow rate

Table 1: Column experiment breakthrough parameters on bed depth

\begin{tabular}{cccccc}
\hline Bed depth & $\begin{array}{c}\text { HRT } \\
(\min )\end{array}$ & $\begin{array}{c}\text { tb } \\
(\mathrm{min})\end{array}$ & $\begin{array}{c}\mathrm{Vb} \\
(\mathrm{ml})\end{array}$ & $\begin{array}{c}\text { texh } \\
(\mathrm{min})\end{array}$ & $\begin{array}{c}\text { Vexh } \\
(\mathrm{ml})\end{array}$ \\
\hline $3 \mathrm{~cm}$ & 2.12 & 6 & 30 & 32 & 160 \\
$5 \mathrm{~cm}$ & 3.53 & 26 & 130 & 60 & 300 \\
$7 \mathrm{~cm}$ & 4.95 & 42 & 210 & 80 & 400 \\
\hline
\end{tabular}

\subsection{Effect of flow rate on breakthrough curve}

The influent $\mathrm{MB}$ and the bed depth are set up to be constant at $50 \mathrm{ppm}$ and $5 \mathrm{~cm}$ respectively to study the flow rate effect on MB removal. Column operation is then run in three different flow rates which are $1.5,2.5$ and $3.5 \mathrm{ml} / \mathrm{min}$. The results obtained are plotted for breakthrough curves as shown in Figure 4. In Figure 4, the adsorption bed is exhausted within a very short time $(\sim 1 \mathrm{hr})$ after the breakthrough occurred, which indicated that the adsorption zone is almost saturated at the time of exhaustion. These types of breakthrough curves are highly desirable. The breakthrough times (corresponding to $\mathrm{C} / \mathrm{C}_{0}=0.100$ ) are found to be 60,25 and 24 minutes for 1.5 , 2.5 and $3.5 \mathrm{ml} / \mathrm{min}$ flow rate, respectively. The exhausted times (corresponding to $\mathrm{C} / \mathrm{C}_{0}=0.995$ ) are 133,60 and 50 minutes, respectively. The corresponding volumes of wastewater treated at breakthrough point are 300,125 and 120 $\mathrm{ml}$, respectively and at exhaust point are 665, 300, and 250 $\mathrm{ml}$, respectively

. Figure 4 indicates that the higher flow rate reached the breakthrough faster compared to the lower flow rate and the column exhausted time elevated significantly with the flow rate reduction. At low rate of influent, the contact time of $\mathrm{MB}$ with sugarcane bagasse is greater thus higher MB ions removal in column occurred. It is observed that the breakthrough curves became steeper as the flow rate increased. Breakthrough time reaching saturation is increased at lower flow rates. Although MB adsorption is a fast process, diffusion effects are lower due to the insufficient residence time of dyes in the column at higher flow rates. Hence lower flow rates are desirable for the effective removal of MB in column mode.
Significantly, the basis of mass transfer fundamentals, capacity can be interpreted by the diversity of the breakthrough curve slope along with the adsorption capability as well. According to [11], the rate of mass transfer increased with the flow rate thus resulted in expanding amount of dye adsorbed onto the adsorbent bed, therefore the column get exhausted faster with higher flow rate. As shown in Table 2, the column achieved exhaustion condition faster for 3.5 $\mathrm{ml} / \mathrm{min}$ which is within 50 minutes compared to 133 minutes for $1.5 \mathrm{ml} / \mathrm{min}$ flow rate. This indicates that lower flow rate is more effective to absorb larger amount of MB compared to higher flow rate.

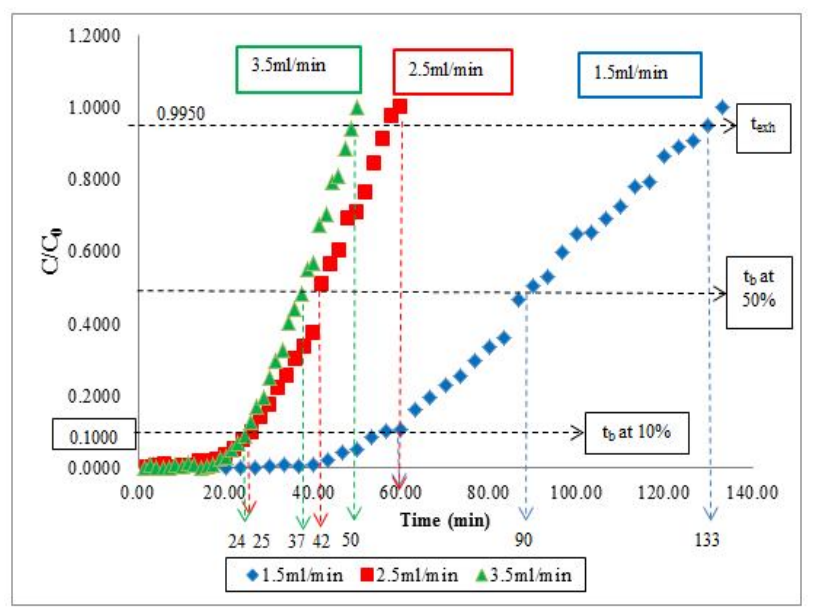

Figure 4: Flow rate effect breakthrough curve on sugarcane bagasse $\mathrm{MB}$ adsorption at $\mathrm{C}_{0}=50 \mathrm{mg} / \mathrm{L}$ and $5 \mathrm{~cm}$ bed depth

Table 2: Column breakthrough parameters on flow rate

\begin{tabular}{cccccc}
\hline Flow rate & $\begin{array}{c}\text { HRT } \\
(\min )\end{array}$ & $\begin{array}{c}\text { tb } \\
(\min )\end{array}$ & $\begin{array}{c}\mathrm{Vb}_{\mathrm{b}} \\
(\mathrm{ml})\end{array}$ & $\begin{array}{c}\text { texh } \\
(\mathrm{min})\end{array}$ & $\begin{array}{c}\text { Vexh } \\
(\mathrm{ml})\end{array}$ \\
\hline $1.5 \mathrm{ml} / \mathrm{min}$ & 5.89 & 60 & 300 & 133 & 665 \\
$2.5 \mathrm{ml} / \mathrm{min}$ & 3.53 & 25 & 125 & 60 & 300 \\
$3.5 \mathrm{ml} / \mathrm{min}$ & 2.52 & 24 & 120 & 50 & 250 \\
\hline
\end{tabular}

\subsection{Thomas model}

Generally, in order to calculate the maximum solid-phase concentration representing the adsorbent maximum adsorption capability and to gain concentration-time profile or a breakthrough curve, column experiments should be conducted [12]. According to [9], a highly convenient model used to regulate the ultimate solid phase concentration of solute on the sorbent and the rate constant for an adsorption column is the Thomas model, which is developed by Thomas.

As tabulated in Table 3, the numbers of $\mathrm{R}^{2}$ values are significantly high for all column system simulation at range 0.95-1.00 This indicates that all breakthrough curves are wellpredicted by the Thomas model as plotted in Figure 5 and 6. The phenomenon of axial dispersion is reduced by the uniform size of adsorbent thus the dye solution are distributed evenly and made the Thomas model suitable.

Thomas model parameters obtained are tabulated in Table 3 where $\mathrm{k}_{\mathrm{Th}}$ and $\mathrm{q}_{0}$ represent the Thomas rate constant and the equilibrium MB uptake respectively. Column adsorption capacity are recorded as $\mathrm{q}_{0}$ and noticed that the operation with the highest bed depth recorded the largest $\mathrm{q}_{0}$ which is 235.634 
$\mathrm{mg} \mathrm{g}^{-1}$ at $7 \mathrm{~cm}$ bed depth. As for the flow rate effect, the highest $\mathrm{q}_{0}$ is recorded at the lowest flow rate, $1.5 \mathrm{ml} / \mathrm{min}$ giving the $\mathrm{q}_{0}$ value of $344.905 \mathrm{mg} \mathrm{g}^{-1}$.

With flow rate increasing, the value of $\mathrm{q}_{0}$ decreased but the value of $k_{\mathrm{Th}}$ increased. As the bed depth increased, the value of $\mathrm{q}_{0}$ increased significantly while the value of $\mathrm{k}_{\mathrm{Th}}$ decreased significantly. Thus lower flow rate and higher bed depth increased the adsorption of MB on sugarcane bagasse.

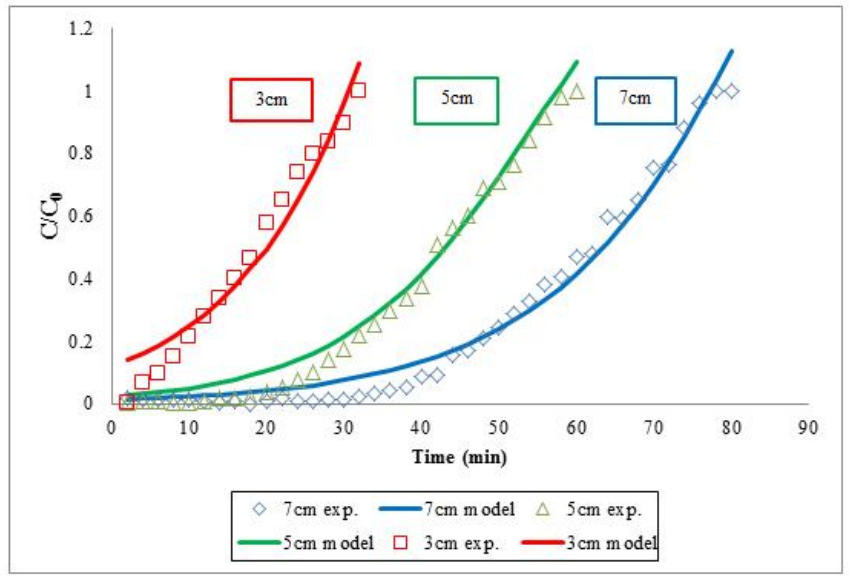

Figure 5:Nonlinear Thomas model curves on various bed depths

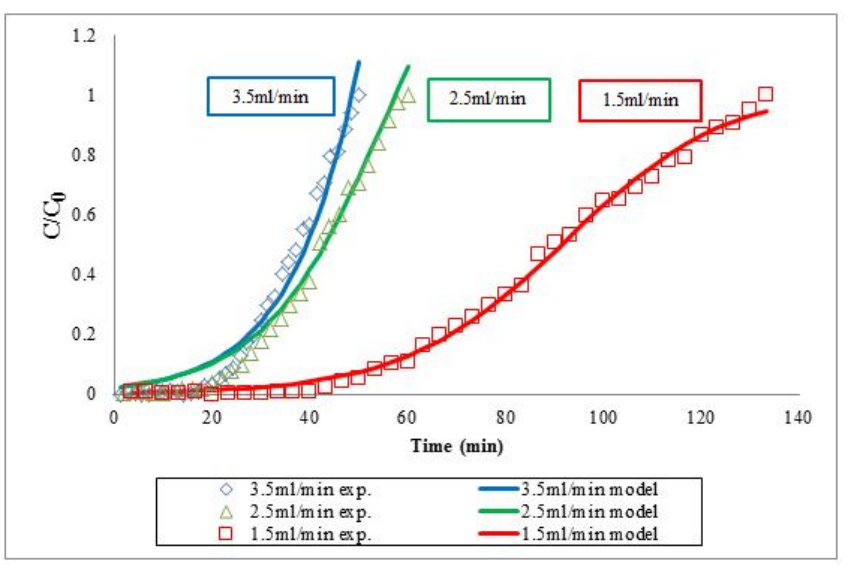

Figure 6:Nonlinear Thomas model curves on various flow rates

Table 3: Thomas model parameters

\begin{tabular}{|c|c|c|c|c|c|c|}
\hline Dye & Adsorbent & \multicolumn{2}{|c|}{ Parameter } & $\begin{array}{c}\mathrm{k}_{\mathrm{Th}} \\
\mathrm{mL} \mathrm{mg}^{-1} \mathrm{~min}^{-1}\end{array}$ & $\begin{array}{c}\mathrm{q}_{0} \\
\mathrm{mg} \mathrm{g}^{-1}\end{array}$ & $\mathrm{R}^{2}$ \\
\hline \multirow{6}{*}{ MB } & \multirow{6}{*}{ SB } & \multirow{3}{*}{ bed depth } & $3 \mathrm{~cm}$ & 0.3720 & 161.472 & 0.95 \\
\hline & & & $5 \mathrm{~cm}$ & 0.2572 & 189.590 & 0.98 \\
\hline & & & $7 \mathrm{~cm}$ & 0.1808 & 235.634 & 0.98 \\
\hline & & \multirow{3}{*}{ flow rate } & $1.5 \mathrm{ml} / \mathrm{min}$ & 0.0879 & 344.905 & 1.00 \\
\hline & & & $2.5 \mathrm{ml} / \mathrm{mm}$ & 0.2572 & 189.585 & 0.98 \\
\hline & & & $3.5 \mathrm{ml} / \mathrm{min}$ & 0.4594 & 164.965 & 0.97 \\
\hline
\end{tabular}

\subsection{Yoon-Nelson model}

This Yoon-Nelson model assumes that the reduction in the possibility of each absorber to be absorbed is comparable to the feasibility of adsorption and breakthrough in the adsorbent [13]. This model is also reliable as well as the Thomas model since it gave acceptable fit to the empirical data. Additionally, this model expected to develop identical $\mathrm{R}^{2}$ values since it predicts the similar uptake capacity and $C_{t} / C_{i}$ values for a particular data set.

As tabulated in Table 4, the numbers of $\mathrm{R}^{2}$ values are significantly high for all column system simulation at range 0.99-1.00 This indicates that all breakthrough curves are wellpredicted by the Yoon-Nelson model as plotted in Figure 7 and 8.

By referring to Table 4, the Yoon-Nelson parameters is presented by $k_{Y N} w h i c h$ refers to Yoon-Nelson rate constant, while time requisite for $50 \%$ breakthrough is represented by $\tau$. Time required for $50 \%$ breakthrough is recorded highest at the lowest flow rate which is 90 minutes at $1.5 \mathrm{ml} / \mathrm{min}$ flow rate compared to 42 and 37 minutes for 2.5 and $3.5 \mathrm{ml} / \mathrm{min}$ flow rate, respectively. This model prediction issimilar to the $50 \%$ breakthrough time from bed depth experimental finding which are 92,42 and 37 minutes for $1.5,2.5$ and $3.5 \mathrm{ml} / \mathrm{min}$ flow rate, respectively.

The significant output from Yoon-Nelson model are the regression coefficient value $\left(\mathrm{R}^{2}\right)$ and time required for $50 \%$ breakthrough $(\tau)$. The nonlinear plots of Yoon-Nelson model produced best fit with $\mathrm{R}^{2}$ values of $0.99-1.00$ for all column systems. The $\mathrm{R}^{2}$ values are important to show that the experimental data is well-predicted. While the $\tau$ values are used in comparison to the time required for $50 \%$ breakthrough from experimental findings. As presented in Table 4, $\tau$ values for bed depth study are 20, 42, and 62 minutes for 3, 5 and 7 $\mathrm{cm}$ bed depth, respectively. Similar values are recorded from experiment findings which 18, 42 and 62 minutes for 3, 5 and $7 \mathrm{~cm}$ bed depth, respectively. As for flow rate study, the $\tau$ values areexactly the same to flow rate experimental finding which are 90, 42, and 37 minutes for $1.5,2.5$ and $3.5 \mathrm{ml} / \mathrm{min}$ respectively.

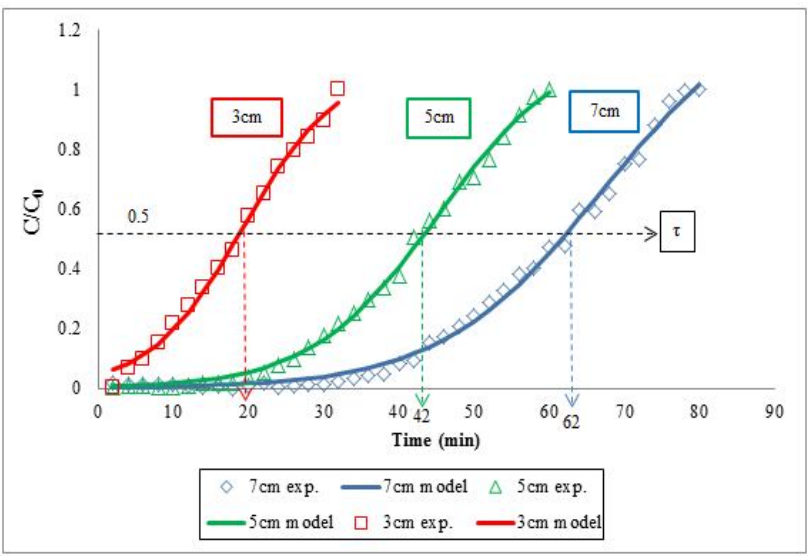

Figure 7: Nonlinear Yoon-Nelson model curves on various bed depths 


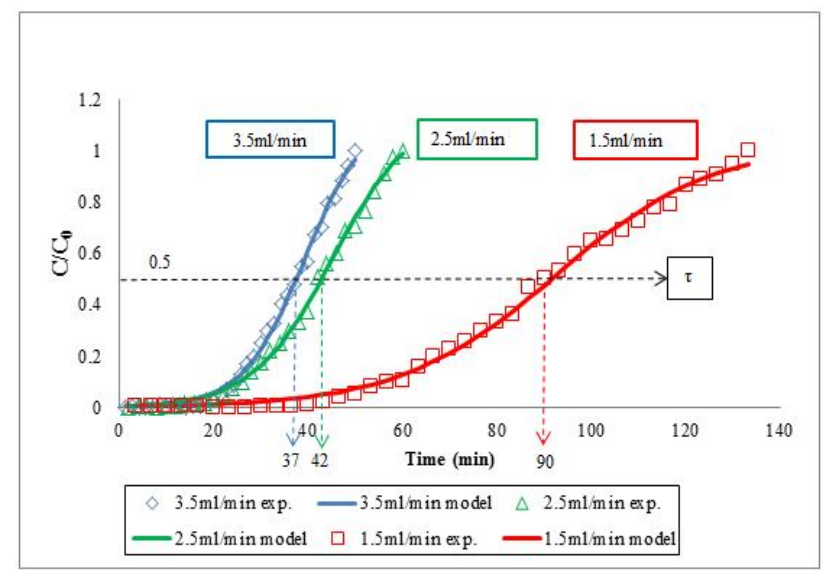

Figure 8: Nonlinear Thomas model curves on various flow rates

\begin{tabular}{|c|c|c|c|c|c|c|c|}
\hline \multirow{2}{*}{ Dye } & Adsorbent & \multicolumn{2}{|c|}{ Parameter } & $\begin{array}{c}\mathrm{k}_{\mathrm{YN}} \\
\mathrm{min}^{-1}\end{array}$ & $\begin{array}{c}\tau \\
\min \end{array}$ & $\begin{array}{c}\mathrm{t}_{50 \%} \text { exp } \\
\min \end{array}$ & $\mathrm{R}^{2}$ \\
\hline \multirow{3}{*}{$\mathrm{MB}$} & \multirow{3}{*}{$\mathrm{SB}$} & bed & $3 \mathrm{~cm}$ & 0.00040 & 20 & 18 & 0.99 \\
& & & $5 \mathrm{~cm}$ & 0.00029 & 42 & 42 & 1.00 \\
& & $7 \mathrm{~cm}$ & 0.00023 & 62 & 62 & 1.00 \\
\cline { 3 - 8 } & & flow & $1.5 \mathrm{ml} / \mathrm{min}$ & 0.00009 & 90 & 90 & 1.00 \\
& & rate & $2.5 \mathrm{ml} / \mathrm{min}$ & 0.00029 & 42 & 42 & 1.00 \\
& & $3.5 \mathrm{ml} / \mathrm{min}$ & 0.00053 & 37 & 37 & 1.00 \\
\hline
\end{tabular}

Table 4 Yoon-Nelson model parameters

\section{CONCLUSION}

This experiment has been carried out with two different variables which bed depth effect and flow rate effect on MB dye. From the results analysis, it is concluded that objectives of the study have achieved which are to check the applicability of sugarcane bagasse as an adsorbent for the removal of dyes in wastewater and to determine effect of column parameters for MB removal by sugarcane bagasse. This can be seen by the results obtained and the pattern of the breakthrough curves plotted from the data obtained from experiments illustrated is closely similar to the typical breakthrough curve pattern. The other objective of this study also achieved which to simulate the experimental data to the column mathematical models, such as Thomas and YoonNelson. From this study, it is concluded that:

- As in the bed depth effect study, the conclusion that can be made is the efficiency of the column operation can be enhanced by the increasing of the bed depth. The higher the bed depth will increase the adsorption capacity thus served larger volume of MB removal.

- The flow rate effect study on MB removal resulted that the higher capacity of dye adsorption is produced by the lower flow rate applied. This is because the low flow rate increased the contact time between dye and the adsorbent. The exhaustion point is increased at lower flow rates. Although MB adsorption is a fast process, diffusion effects are lower due to the insufficient residence time of MB in the column at higher flow rates. Hence lower flow rates are desirable for the effective removal of $\mathrm{MB}$ in column mode.

- By applying the experimental data to the Thomas model, the model fitted the experimental data well as it provided the regression coefficient $\mathrm{R}^{2}$ value range of 0.95-1.00.

- The model fit the experimental data for the YoonNelson model application, The regression coefficient value $\mathrm{R}^{2}$ obtained is $0.99-1.00$. In addition, the $\tau$ value obtained from the Yoon-Nelson model represent the time needed for $50 \%$ breakthrough and is almost similar to the $50 \%$ breakthrough time obtained from the experimental findings for both bed depth and flow rate study.

Generally, untreated sugarcane bagasse used in this study is easily available especially in countryside and it is invaluable. Therefore, it is an ideal source of adsorbent which is economic and environmental safe since no chemical process involved. Small scale industries that originated dyes as their discharged can make used of this potential adsorbent, nevertheless specific pre-treatment process might be involved to improve the performance and enhance the adsorption capacity to meet the industry requirement Thus, data obtained from this study might be useful in designing and fabrication of and economically cheap and environmental friendly treatment process using column operation systems for the removal of dyes from diluted industry discharged.

\section{REFERENCES}

[1] Fu, Yuzhu, and T. Viraraghavan. "Fungal decolorization of dye wastewaters: a review." Bioresource technology 79, no. 3. 2001, pp. 251-262.

[2] Banat, Ibrahim M., Poonam Nigam, Datel Singh, and Roger Marchant. "Microbial decolorization of textiledyecontaining effluents: a review." Bioresource technology 58, no. 3, 1996, pp. 217-227.

[3] Vadivelan, V., and K. Vasanth Kumar. "Equilibrium, kinetics, mechanism, and process design for the sorption of methylene blue onto rice husk." Journal of colloid and interface science 286, no. 1, 2005, pp. 90-100.

[4] Robinson, Tim, Geoff McMullan, Roger Marchant, and Poonam Nigam. "Remediation of dyes in textile effluent: a critical review on current treatment technologies with a proposed alternative." Bioresource technology 77 , no. 3, 2001, pp. 247-255.

[5] Uddin, Md Tamez, Md Rukanuzzaman, Md Maksudur Rahman Khan, and Md Akhtarul Islam. "Adsorption of methylene blue from aqueous solution by jackfruit (Artocarpus heteropyllus) leaf powder: a fixed-bed column study." Journal of environmental management 90, no. 11, 2009, pp. 3443-3450.

[6] Kumar, Anupama, N. N. Rao, and S. N. Kaul. "Alkalitreated straw and insoluble straw xanthate as low cost adsorbents for heavy metal removal-preparation, 
Noor Afifah Husna Md Hussain et al., International Journal of Emerging Trends in Engineering Research, 8(1.1), 2020,90 - 96

characterization and application." Bioresource Technology 71, no. 2, 2000, pp, 133-142.

[7] Crini, Gregorio. "Non-conventional low-cost adsorbents for dye removal: a review." Bioresource technology 97, no. 9, 2006, pp. 1061-1085.

[8] Ngah, WS Wan, and M. A. K. M. Hanafiah. "Biosorption of copper ions from dilute aqueous solutions on base treatedrubber (Hevea brasiliensis) leaves powder: kinetics, isotherm, and biosorption mechanisms." Journal of Environmental Sciences 20, no. 10, 2008, pp. 11681176.

[9] Che Ibrahim, Shariff. "Treatment of oily and dye wastewater with modified barley straw." $\mathrm{PhD}$ diss., Curtin University, 2010.

[10]Han, Runping, Yuanfeng Wang, Weihong Yu, Weihua Zou, Jie Shi, and Hongmin Liu. "Biosorption of methylene blue from aqueous solution by rice husk in a fixed-bed column." Journal of hazardous materials 141, no. 3, 2007, pp.713-718.

[11] Ko, Danny CK, John F. Porter, and Gordon McKay. "Optimised correlations for the fixed-bed adsorption of metal ions on bone char." Chemical engineering science 55, no. 23, 2000, pp.5819-5829.

[12] Yan, Guangyu, T. Viraraghavan, and Min Chen. "A new model for heavy metal removal in a biosorption column." Adsorption Science \& Technology 19, no. 1, 2001, pp. 25-43.

[13] Xu, Zhe, Jian-guo Cai, and Bing-cai Pan. "Mathematically modeling fixed-bed adsorption in aqueous systems." Journal of Zhejiang University SCIENCE A 14, no. 3, 2013, pp. 155-176. 